Check for updates

Cite this: RSC Adv., 2017, 7, 55215

Received 13th September 2017 Accepted 29th November 2017

DOI: 10.1039/c7ra10199f

rsc.li/rsc-advances

\section{Nanosilica-supported thiosemicarbazide- glutaraldehyde polymer for selective Au(III) removal from aqueous solution}

\begin{abstract}
Gengwei Zhang, ${ }^{b}$ Yang Zhou, (D) *a Zhao Ding, ${ }^{c}$ Likang Fu ${ }^{b}$ and Shixing Wang ${ }^{\star b}$
A new adsorbent thiosemicarbazide/nanosilica composite was synthesized via a facile two-step reaction, including the functionalization of silica nanoparticles via amino groups, and crosslinking the thiosemicarbazide with glutaraldehyde onto the amino functionalized silica nanoparticles. The adsorption capability of the adsorbent for $\mathrm{Au}(\mathrm{II})$ ions was investigated. Fourier transform infrared, X-ray photoelectron spectroscopy and thermogravimetric analysis were used to characterize the adsorbent. Experimental results indicated that nanocomposites exhibited highly selective and efficient adsorption for $\mathrm{Au}(\mathrm{III})$. The equilibrium data fitted well with the Langmuir isotherm and the obtained kinetic data obeyed the pseudo-second-order kinetics model. The maximum adsorption capacity was $4.3 \mathrm{mmol} \mathrm{g}$ at $\mathrm{pH}$ 2. The adsorbent can still keep high adsorption capability after five recycling rounds. The adsorption mechanisms were proposed as the synergistic effect of ionic interaction and chelation.
\end{abstract}

\section{Introduction}

Gold is one of the precious metals that has been widely used in high-tech industries, catalysts in various chemical processes, electrical and electronic industries, agriculture and medicine. ${ }^{1}$ The need for recycling or recovery of Au(III) economically has increased due to the increases in industrial demand and its value. The detection and recovery of $\mathrm{Au}(\mathrm{III})$, however, are not simple issues because of its low concentration in environmental, geological and metallurgical materials. So there is a strong economic motivation for the recovery of $\mathrm{Au}$ (III) from aqueous solution. Some methods such as solvent extraction, ${ }^{2}$ adsorption, $^{3}$ precipitation $^{4}$ and membrane separation ${ }^{5}$ have been reported for the recovery of gold from aqueous solutions. Among these methods, adsorption is regarded as an effective technology due to its low energy consumption, low cost, ease of operation and high efficiency.

A good adsorbent should consist of a stable matrix and suitable groups. Amino groups are usually utilized as efficient chelating groups for recovery of $\mathrm{Au}(\mathrm{III}){ }^{6-8}$ In recent years, chelating resins with various functional groups have been widely used for recovery of gold due to their high selectivity. ${ }^{9}$ The resins containing groups with nitrogen or sulphur atom

${ }^{a}$ School of Textile Science and Engineering, National Engineering Laboratory for Advanced Yarn and Clean Production, Wuhan Textile University, Wuhan 430200, China.E-mail: zhouyangnano@163.com

${ }^{b}$ Faculty of Metallurgical and Energy Engineering, Kunming University of Science and Technology, Kunming 650093, China.E-mail: wsxkm@sina.com

${ }^{c}$ Department of Mechanical, Materials and Aerospace Engineering, Illinois Institute of Technology, Chicago 60616, USA can selective chelating with precious metals according to Pearson's hard soft acid-base theory. ${ }^{10}$ However, there are some disadvantages of resin matrix, such as swelling, sensitivity to chemical environment and low mechanical stability. ${ }^{\mathbf{1 1}}$ Inorganic supports, therefore, are suggested to take place of resin matrix due to advantages of no swelling and good mechanical stability. Furthermore, inorganic substrate can get unique opportunities by immobilizing of organic functional groups. ${ }^{12}$ Among different inorganic supports, nanosilica is known to be one of the most ideal materials due to its advantages of reliable chemical, mechanical and thermal stability, economy, extremely large surface area, short diffusion distance and facile surface modification. ${ }^{\mathbf{1 3 , 1 4}}$

In this study, thiosemicarbazide/nanosilica composite (TSCSNC) was synthesized via crosslinking the thiosemicarbazide with glutaraldehyde onto the surface of the amino functionalized silica nanoparticles. We investigated systemically the adsorption properties such as selective capture in coexisting other metal ions solution, adsorption efficiency with different $\mathrm{pH}$ value and recycling times for $\mathrm{Au}(\mathrm{III})$. The adsorption mechanism, adsorption kinetics and isotherms were also discussed to support the proposal of synergistic effect of ionic interaction and chelation.

\section{Experimental section}

\subsection{Chemicals}

Silica nanoparticles (SNPs), 3-aminopropyltriethoxysilane (APTES) and thiosemicarbazide (TSC) were obtained from Aladdin-reagent Co., Ltd. Ethanol and glutaraldehyde (GTA) were obtained from Tianjin Chemical Regents, Inc. All reagents 
were analytical grade. Metal solutions were prepared by diluting standard solutions with distilled water. These stock solutions were adjusted to the desired $\mathrm{pH}$ values by adding $\mathrm{HCl}$ or $\mathrm{NaOH}$ solutions.

\subsection{Preparation of TSC-SNC adsorbent}

The preparation process of the adsorbent was presented in Scheme 1. SNPs $(3.0 \mathrm{~g})$, ethanol $(50 \mathrm{~mL})$ and APTES $(6 \mathrm{~mL})$ were added to a $250 \mathrm{~mL}$ three-necked flask. The suspension was stirred and refluxed for $18 \mathrm{~h}$. Then the solid was separated by centrifugation, washed with ethanol and dried to give APTESSNPs. In the next step, for preparation thiosemicarbazide/silica nanocomposite, $2.8 \mathrm{~g}$ of APTES-SNPs was dispersed in $50 \mathrm{~mL}$ distilled water in a $250 \mathrm{~mL}$ three-necked flask, followed by addition of TSC $(6 \mathrm{~g})$ and GTA $(10 \mathrm{~mL})$. The solution was adjusted to $\mathrm{pH} 8 \mathrm{using}$ ammonia and stirred at $90{ }^{\circ} \mathrm{C}$ for $9 \mathrm{~h}$. The resulting final product (TSC-SNC) was washed with deionized water and dried under vacuum.

\subsection{Adsorption experiments}

All gold adsorption experiments were performed in a thermostat steam bath vibrator at a shaking speed of $240 \mathrm{rpm}$ at $25{ }^{\circ} \mathrm{C}$. The adsorption amount $\left(q\right.$, mmol $\left.\mathrm{g}^{-1}\right)$ of metal ions on the adsorbent and adsorption percent $(R, \%)$ were measured by the formula:

$$
\begin{gathered}
q=V\left(C_{0}-C_{t}\right) / m \\
R=\left(C_{0}-C_{t}\right) / C_{t}
\end{gathered}
$$

where $V(\mathrm{~L})$ is the volume of $\mathrm{Au}(\mathrm{III})$ solution and $m(\mathrm{~g})$ represents the mass of TSC-SNC. $C_{0}$ and $C_{t}\left(\mathrm{mmol} \mathrm{L}^{-1}\right)$ are the initial and final concentration of $\mathrm{Au}(\mathrm{III})$ solution, respectively. All adsorption experiments were performed in three replicates.

To evaluate the effect of $\mathrm{pH}, 20 \mathrm{mg}$ of TSC-SNC was added into a series of flasks containing $200 \mathrm{~mL}$ solutions at $100 \mathrm{mg} \mathrm{L}^{-1}$ $\mathrm{Au}(\mathrm{III})$ concentration, the initial $\mathrm{pH}$ was adjusted using $\mathrm{NaOH}$ and $\mathrm{HCl}$ solution to the designated values from 2 to 10 . The experiments were performed for $5 \mathrm{~h}$ and then the concentration of $\mathrm{Au}(\mathrm{III})$ in the solutions was determined.

To evaluate the selectivity of TSC-SNC, $20 \mathrm{mg}$ of TSC-SNC was added into $200 \mathrm{~mL}$ solutions containing a mixture of $\mathrm{Au}(\mathrm{III})$, $\mathrm{Cu}$ (II), $\mathrm{Zn}$ (II) and $\mathrm{Pb}$ (II) at $\mathrm{pH} 2$. The initial concentration of the coexisting metal ion is $100 \mathrm{mg} \mathrm{L}^{-1}$, respectively. The mixtures were shaken for $5 \mathrm{~h}$, then the concentrations of the coexisting metal ion in the solutions were determined.

For adsorption isotherms, $20 \mathrm{mg}$ of TSC-SNC was added into a series of flasks containing $200 \mathrm{~mL}$ solutions at pH 2, the initial $\mathrm{Au}(\mathrm{III})$ concentration varied in the range of 80 to $160 \mathrm{mg} \mathrm{L}^{-1}$. The mixtures were shaken for $5 \mathrm{~h}$, and the concentration of $\mathrm{Au}(\mathrm{III})$ in the solutions was determined.

Adsorption kinetics experiments were performed by adding $20 \mathrm{mg}$ of TSC-SNC into a series of flasks containing $200 \mathrm{~mL}$ solutions at $\mathrm{pH} 2$ and $100 \mathrm{mg} \mathrm{L}^{-1} \mathrm{Au}(\mathrm{III})$ concentration. The concentration of $\mathrm{Au}(\mathrm{III})$ in solutions after different time intervals (2-120 min) was determined.

The recycling was tested by adding $20 \mathrm{mg}$ of TSC-SNC to a flask containing $200 \mathrm{~mL}$ solutions at $\mathrm{pH} 2$ and $100 \mathrm{mg} \mathrm{L}^{-1}$ $\mathrm{Au}(\mathrm{III})$ concentration. After $5 \mathrm{~h}$ shaking, the concentration of $\mathrm{Au}(\mathrm{III})$ in the solutions was determined. The Au loaded TSC-SNC was separated and then oscillated for $5 \mathrm{~h}$ with $0.1 \mathrm{M}$ thiourea and $0.1 \mathrm{M} \mathrm{HNO}_{3}$ solution. The adsorbent was then washed with distilled water, dried and reused in adsorption experiment. The whole process repeated 5 times by using the same adsorbent.

\subsection{Characterization}

FTIR was recorded on a FTIR spectrometer (Bruker, Equinox55, Germany). XPS analyses were performed with an electron spectrometer (VG Scientific, ESCALab220i-XL, UK). TGA measurements were conducted on PerkinElmer TGA-7 (USA) thermogravimetric analyzer at a heating rate of $10{ }^{\circ} \mathrm{C} \mathrm{min}^{-1}$. After adsorption, the supernatant was collected and analyzed by inductively coupled plasma atomic emission spectrometry (ICPAES) (Leema, Prodigy 7, USA). The zeta potential of TSC-SNC in the aqueous solution was analyzed on a Zeta Plus potentiometer (Brookhaven, USA).

\section{Results and discussion}

\subsection{Characterization of TSC-SNC}

Fig. 1 shows the FTIR spectra of SNPs, APTES-SNPs and TSCSNC. In the spectra of SNPs, The peak at $3430 \mathrm{~cm}^{-1}$ and $1633 \mathrm{~cm}^{-1}$ were due to the $\mathrm{O}-\mathrm{H}$ stretching vibration and the $\mathrm{O}-\mathrm{H}$ bending vibration of the adsorbed water and silanol groups. The adsorption peak at $1110 \mathrm{~cm}^{-1}$ was corresponded to the $\mathrm{Si}-\mathrm{O}-\mathrm{Si}$ asymmetric stretching vibrations, and the peaks at 800 and $474 \mathrm{~cm}^{-1}$ were attributed to the $\mathrm{Si}-\mathrm{O}-\mathrm{Si}$ symmetric stretching vibrations and bending vibrations, respectively. For APTES-SNPs, the C-H stretching vibration at $2924 \mathrm{~cm}^{-1}$ and

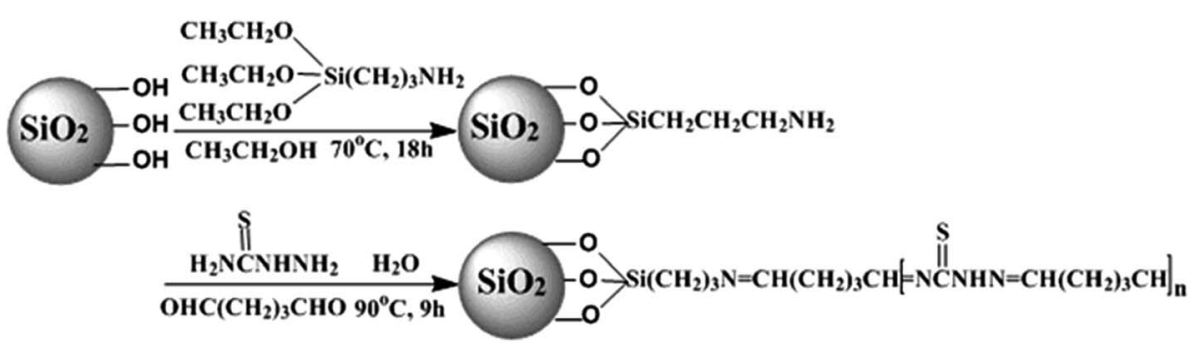

Scheme 1 Preparation process of TSC-SNC adsorbent. 


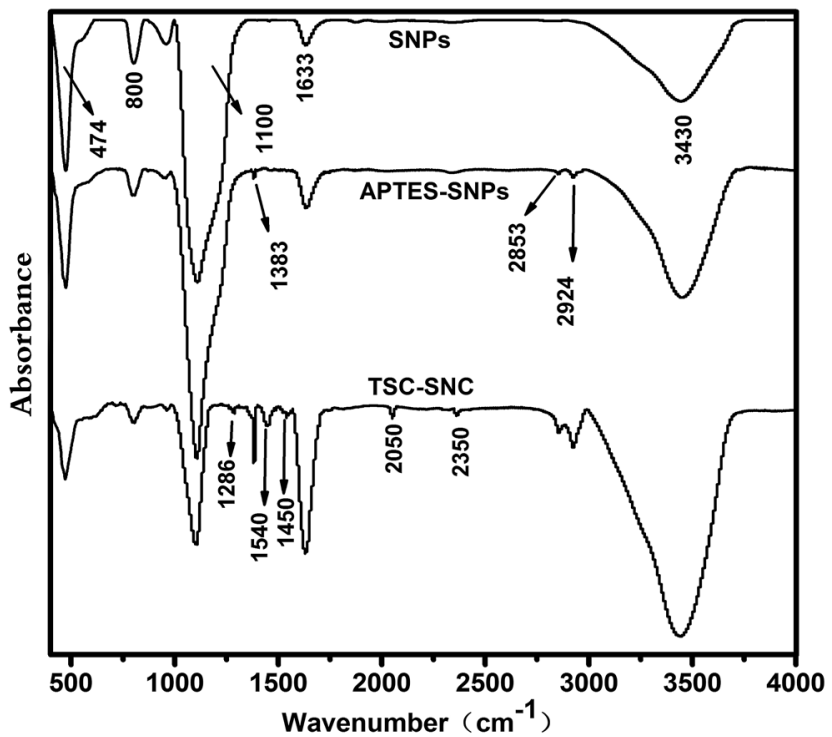

Fig. 1 FT-IR spectra of SNPs, APTES-SNPs and TSC-SNC.

$2853 \mathrm{~cm}^{-1}$, and the $-\mathrm{CH}_{3}$ bending vibrations at $1383 \mathrm{~cm}^{-1}$ demonstrated the organic silane had been successfully grafted on the surface of silica nanoparticles.

In the spectra of TSC-SNC, the peaks at 1286, 1450 and $1540 \mathrm{~cm}^{-1}$ came from $\mathrm{N}-\mathrm{C}=\mathrm{S}, \mathrm{C}-\mathrm{N}$ and $\mathrm{C}=\mathrm{N}$ bonds, respectively. The new peaks at 2050 and $2345 \mathrm{~cm}^{-1}$ were corresponded to $\mathrm{C}=\mathrm{NH}^{+}$and $\mathrm{S}-\mathrm{H}$ bonds respectively attributing to the thione-thiol tautomerism of thioamide groups. ${ }^{15}$ In addition, the peaks at 1633 and $3430 \mathrm{~cm}^{-1}$ were broader owing to the overlap of the peaks of $\mathrm{N}-\mathrm{H}$ stretching and bending vibration and the $\mathrm{O}-\mathrm{H}$ stretching vibration.

X-ray photoelectron spectroscopy was used to clarify the chemical composition of the composites. Fig. 2 shows the widescan spectra for these samples. The characteristic peaks of $O 1 \mathrm{~s}$, C 1s, Si 2 p and Si 2 s were observed in the spectra of SNPs. In comparison with SNPs, the nitrogen peak at $401.2 \mathrm{eV}$ was observed in the spectrum of APTES-SNPs. The spectra of TSCSNC presented S 2p signal at $168.2 \mathrm{eV}$, which arose from the thioamide group. In order to clarify the elemental composition, we measured the XPS spectra of C 1s (Fig. 3). The C 1s signal of APTES-SNPs presented two peaks at 284.6 and $286.2 \mathrm{eV}$, corresponded to $\mathrm{C}-\mathrm{C}(\mathrm{H})$ and $\mathrm{C}-\mathrm{N}$ species. The $\mathrm{C} 1 \mathrm{~s}$ of TSC-SNC can be curve-fitted into five peak components. The new peaks at 285.9, 287.9 and $288.5 \mathrm{eV}$ are corresponded to $\mathrm{C}-\mathrm{S}, \mathrm{C}=\mathrm{N}$ and $\mathrm{C}=\mathrm{S}$ species, respectively, which confirms that thiosemicarbazide-glutaraldehyde has been successfully grafted on the silica nanoparticles.

Fig. 4 shows the TGA analysis of the SNPs, APTES-SNPs and TSC-SNC. The mass loss of TSC-SNPs was $67.7 \%$. While the unfunctionalized SNPs and APTMS-SNPs only show mass losses of $9.1 \%$ and $13.3 \%$, respectively. The mass loss was due to the evaporation of water and decomposition of organic molecules. Based on the TGA curves in Fig. 4, the amount of the thiosemicarbazide-glutaraldehyde polymer in the composite was calculated to be $54.4 \mathrm{wt} \%$.

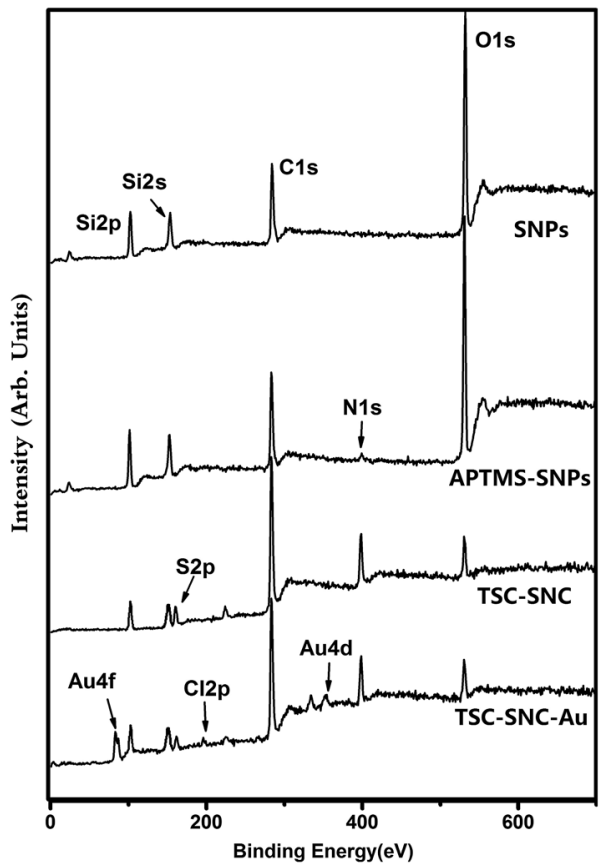

Fig. 2 XPS survey scan of SNPS, APTES-SNPS, TSC-SNC and TSC$\mathrm{SNC}-\mathrm{Au}$

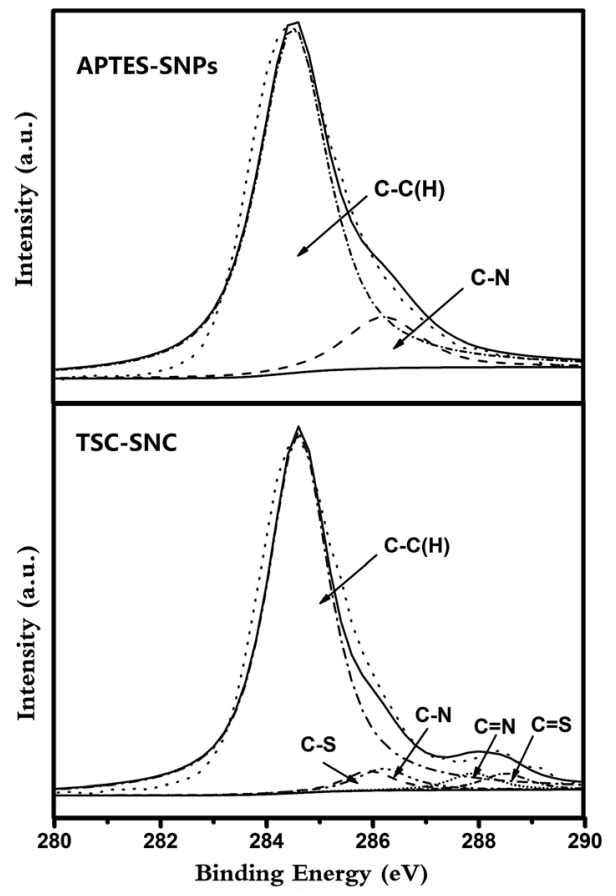

Fig. 3 The C 1s spectra of APTES-SNPs and TSC-SNC.

\subsection{Adsorption behavior of TSC-SNC}

3.2.1 The effect of $\mathbf{p H}$ on adsorption $\mathrm{Au}(\mathrm{III})$. The effect of different $\mathrm{pH}$ value from 2 to 10 on $\mathrm{Au}(\mathrm{III})$ adsorption was studied. At low pH, gold forms $\mathrm{AuCl}_{4}{ }^{-}$complex ions in chloride solution, and chloride-hydroxide complexes of $\mathrm{Au}(\mathrm{III})$ begin to form when $\mathrm{pH}$ is above $4 .^{\mathbf{1 6}}$ Fig. 5 shows that adsorption 


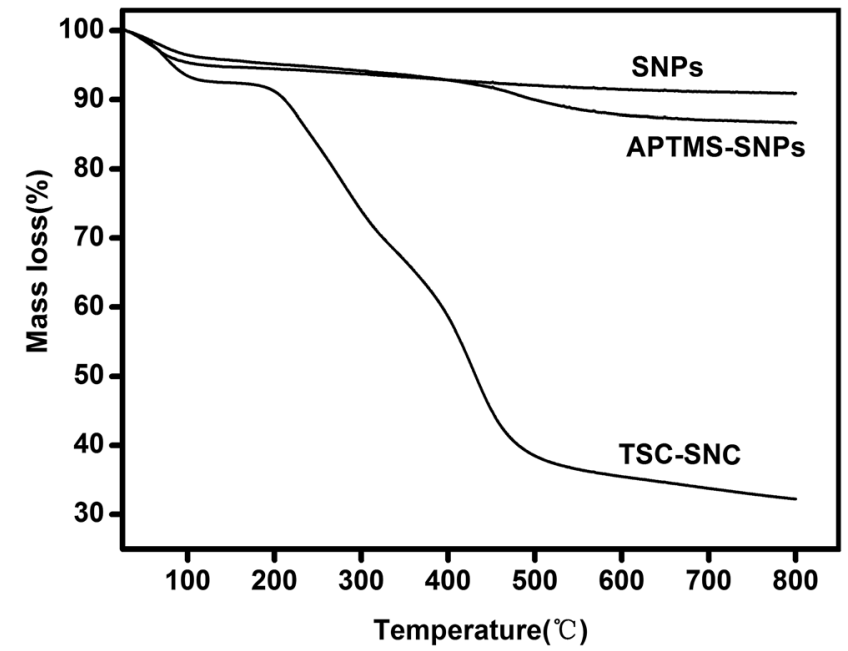

Fig. 4 TGA of SNPS, APTES-SNPs and TSC-SNC.

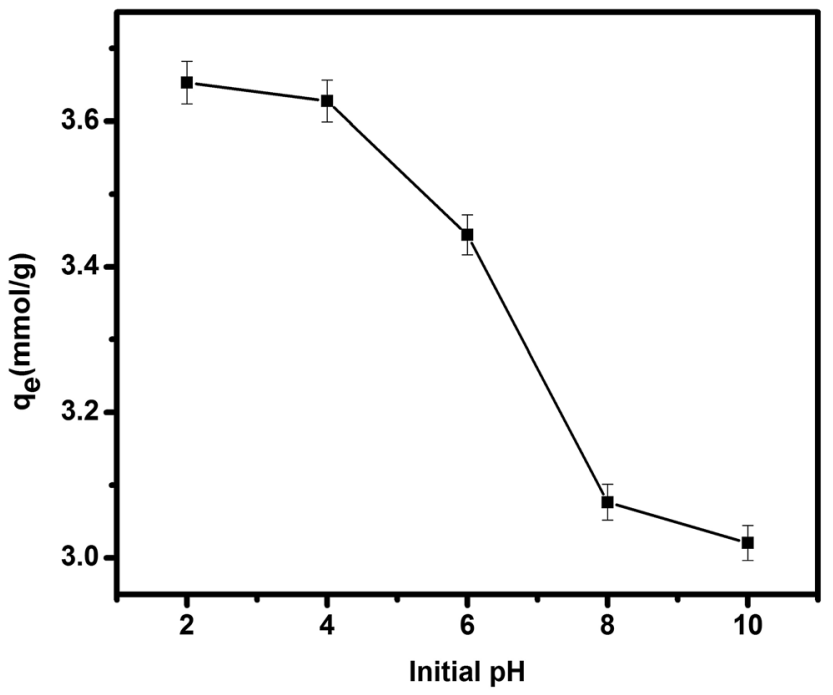

Fig. 5 The effect of $\mathrm{pH}$ on the adsorption of $\mathrm{Au}(\mathrm{III)}, \mathrm{TSC}-\mathrm{SNC}=20 \mathrm{mg}$, $\left[\mathrm{Au}^{3+}\right]=100 \mathrm{mg} \mathrm{L}^{-1}$, adsorption time $=5 \mathrm{~h}$.

capacity markedly decreased with an increase of $\mathrm{pH}$ value of the solution. The optimal $\mathrm{pH}$ for the recovery of $\mathrm{Au}(\mathrm{III})$ was around 2. Fig. 6 shows the effect of $\mathrm{pH}$ on zeta potential of TSC-SNC. The zeta potential of TSC-SNC decreased with the increasing of $\mathrm{pH}$ value. At $\mathrm{pH}=2$, TSC-SNC was positively charged. So most of the amine and thioamide groups on the adsorbent surface were protonated and the adsorbent acquired positively charged surface at low $\mathrm{pH}$, which enhanced the electrostatic attraction between $\mathrm{AuCl}_{4}{ }^{-}$and the adsorbent.

3.2.2 Adsorption selectivity. Au(III) often coexists with other metal ions in aqueous solutions. The investigation of selective adsorption of the TSC-SNC for Au(III) is therefore necessary. To test whether the specificity in the adsorption of $\mathrm{Au}(\mathrm{III})$ is compromised by complex mixtures of other cations, we used the interfere medium containing $\mathrm{Pb}$ (II), $\mathrm{Cu}$ (II) and $\mathrm{Zn}$ (II). The results revealed that the removal percent of $\mathrm{Au}(\mathrm{III})$ was much higher

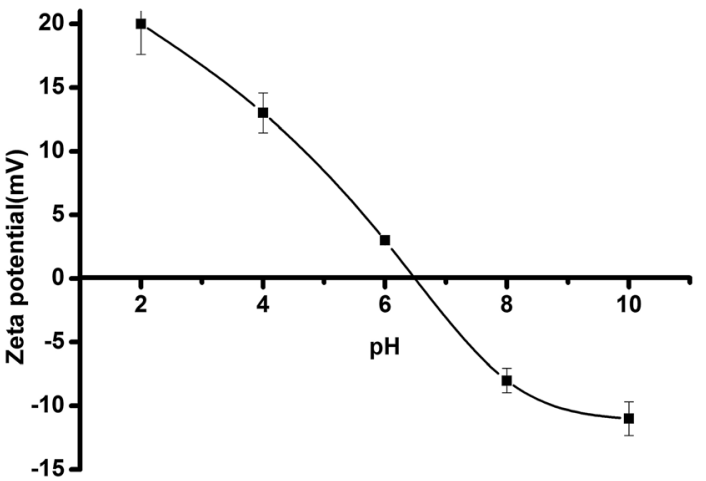

Fig. 6 Effect of $\mathrm{pH}$ on zeta potential values of TSC $-\mathrm{SNC}$, TSC $-\mathrm{SNC}=$ $20 \mathrm{mg},\left[\mathrm{Au}^{3+}\right]=100 \mathrm{mg} \mathrm{L}^{-1}$, adsorption time $=5 \mathrm{~h}$.

than that of the other metal ions, indicating the TSC-SNC is a promising adsorbent for selective recovery of $\mathrm{Au}(\mathrm{III})$ from aqueous solutions (Fig. 7).

3.2.3 Adsorption isotherms. The experimental data of $\mathrm{Au}(\mathrm{III})$ on TSC-SNC was analyzed using Langmuir and Freundlich models. The Langmuir isotherm assumes a monolayer adsorption and all adsorption sites uniformly distributed on a homogeneous surface, ${ }^{17}$ which can be expressed as:

$$
C_{\mathrm{e}} / q_{\mathrm{e}}=1 / q_{0} K_{\mathrm{L}}+C_{\mathrm{e}} / q_{0}
$$

where $C_{\mathrm{e}}\left(\mathrm{mmol} \mathrm{L}^{-1}\right)$ is the equilibrium concentration of $\mathrm{Au}(\mathrm{III})$, $q_{\mathrm{e}}\left(\mathrm{mmol} \mathrm{g}^{-1}\right)$ is the adsorption capacity at equilibrium, $K_{\mathrm{L}}(\mathrm{L}$ $\left.\mathrm{mmol}^{-1}\right)$ and $q_{0}\left(\mathrm{mmol} \mathrm{\textrm {g } ^ { - 1 }}\right)$ are the Langmuir constants involved in adsorption rate and adsorption capacity. While the Freundlich isotherm presumes that the multilayer of the adsorption process occurs on a heterogeneous surface. ${ }^{18}$ Freundlich isotherm can be expressed:

$$
\ln q_{\mathrm{e}}=\ln K_{\mathrm{F}}+1 / n \ln C_{\mathrm{e}}
$$

where $K_{\mathrm{F}}$ and $n$ are Freundlich constants.

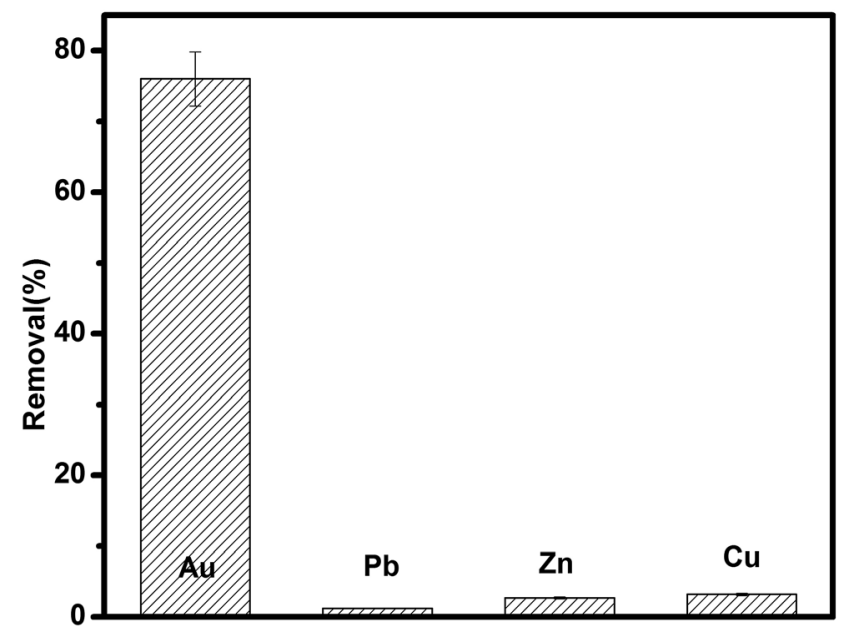

Fig. 7 Selective adsorption of TSC-SNC for Au(III). Ion concentration of $\mathrm{Au}\left({ }^{\prime \prime}\right), \mathrm{Cu}(॥), \mathrm{Zn}(॥)$ and $\mathrm{Pb}(॥)$ is $100 \mathrm{mg} \mathrm{L}^{-1}$, adsorption time $=5 \mathrm{~h}$. 
Table 1 Isotherm parameters for Au(III) adsorption on TSC-SNC

\begin{tabular}{lll}
\hline Isotherms & Parameters & $R^{2}$ \\
\hline Langmuir & $q_{\mathrm{o}}=4.32 \mathrm{mmol} \mathrm{g}^{-1}$ & 0.991 \\
Freundlich & $\begin{array}{l}K_{\mathrm{L}}=18.1 \mathrm{~L} \mathrm{mmol}^{-1} \\
K_{\mathrm{F}}=4.4 \mathrm{mmol} \mathrm{g}^{-1} \\
n=5.7\end{array}$ & 0.951 \\
&
\end{tabular}

The adsorption data from Langmuir and Freundlich models were collected in Table 1 . It can be seen that the Langmuir model (Fig. 8a) fits better than the Freundlich model (Fig. 8b). Therefore, the adsorption of $\mathrm{Au}(\mathrm{III})$ on TSC-SNC can be regarded as a monolayer adsorption, and the maximum adsorption capacity calculated from the Langmuir isotherm was $4.3 \mathrm{mmol} \mathrm{g}^{-1}$. Table 2 reveals a comparison of adsorption capacity between the TSC-SNC adsorbent and other listed adsorbents reported in the literatures. As can be seen from Table 2, the as-prepared nanocomposite presents an excellent adsorption ability.

3.2.4 Adsorption kinetics. Adsorption kinetic can provide important information on the adsorption behaviors. The Lagergren pseudo-first-order and pseudo-second-order kinetic model were employed to study the adsorption kinetics of $\mathrm{Au}(\mathrm{III})$. These two kinetic models are given as: ${ }^{23}$

$$
\begin{gathered}
\ln \left(q_{1}-q_{t}\right)=\ln \left(q_{\mathrm{e}}\right)-k_{1} t \\
t / q_{t}=1 / k_{2} q_{2}^{2}+t / q_{2}
\end{gathered}
$$

where $q_{1}$ represents the maximum adsorption capacity $\left(\mathrm{mmol} \mathrm{g}^{-1}\right)$ for the pseudo first order adsorption, $q_{2}$ represents the maximum adsorption capacity $\left(\mathrm{mmol} \mathrm{g}^{-1}\right)$ for the pseudosecond-order adsorption, $q_{t}\left(\mathrm{mmol} \mathrm{g}^{-1}\right)$ represents the amounts of $\mathrm{Au}(\mathrm{III})$ adsorbed at any time (min). $k_{1}\left(\mathrm{~min}^{-1}\right)$ is the rate constant of the pseudo-first-order model and $k_{2}$ ( $\mathrm{g} \mathrm{mmol}^{-1} \mathrm{~min}^{-1}$ ) is the pseudo-second-order rate constant.

The kinetic parameters and the correlation coefficients $\left(R^{2}\right)$ were listed in Table 3. Pseudo-second-order model fitted better the adsorption kinetics due to the relative high $R^{2}$ (Fig. 9b). The value of $q_{2}$ calculated from the pseudo-second-order kinetic
Table 2 Comparison of adsorption capacity of TSC-SNC with adsorbents reported in literature

\begin{tabular}{ll}
\hline Sorts of adsorbent & $\begin{array}{l}\text { Adsorption capacity and } \\
\text { corresponding references }\end{array}$ \\
\hline Chelating resin & $0.73 \mathrm{mmol} \mathrm{g}^{-1}$ (ref. 3) \\
& $2.23 \mathrm{mmol} \mathrm{g}^{-1}$ (ref. 19) \\
& $0.25 \mathrm{mmol} \mathrm{g}^{-1}$ (ref. 13) \\
& $53.6 \mathrm{mg} \mathrm{mL}^{-1}$ (ref. 32) \\
& $0.85 \mathrm{mmol} \mathrm{g}^{-1}$ (ref. 20) \\
Chitosan & $0.35 \mathrm{mmol} \mathrm{g}^{-1}$ (ref. 21) \\
& $3.6 \mathrm{mmol} \mathrm{g}^{-1}$ (ref. 28) \\
& $30.95 \mathrm{mg} \mathrm{g}^{-1}$ (ref. 29) \\
& $198.5 \mathrm{mg} \mathrm{g}^{-1}$ (ref. 30) \\
& $1.48 \mathrm{mmol} \mathrm{g}^{-1}$ (ref. 22) \\
& $1.15 \mathrm{mg} \mathrm{g}^{-1}$ (ref. 25) \\
& $108.34 \mathrm{mg} \mathrm{g}^{-1}$ (ref. 34) \\
Carbon & $1076.64 \mathrm{mg} \mathrm{g}^{-1}$ (ref. 37) \\
& $0.637 \mathrm{mmol} \mathrm{g}^{-1}$ (ref. 31) \\
Polymer or gel & $2.8 \mathrm{mmol} \mathrm{g}^{-1}$ (ref. 33) \\
& $0.8 \mathrm{mmol} \mathrm{g}^{-1}$ (ref. 40) \\
Biosorbent & $0.05 \mathrm{~mol} \mathrm{~kg}^{-1}$ (ref. 26) \\
& $0.45 \mathrm{mmol} \mathrm{g}^{-1}$ (ref. 35) \\
Nanoparticles & $784 \mathrm{mg} \mathrm{g}^{-1}$ (ref. 36) \\
TSC-SNC & $499.22 \mathrm{mg} \mathrm{g}^{-1}$ (ref. 27) \\
& $0.4 \mathrm{mmol} \mathrm{g}^{-1}$ (ref. 38) \\
$208.3 \mathrm{mg} \mathrm{g}^{-1}$ (ref. 39) \\
$4.3 \mathrm{mmol} \mathrm{g}^{-1}$ this study
\end{tabular}

Table 3 Kinetic models for Au(II) adsorption on TSC-SNC

\begin{tabular}{lll}
\hline Models & Model parameters & $R^{2}$ \\
\hline Pseudo-first-order & $q_{1}=1.6 \mathrm{mmol} \mathrm{g}^{-1}$ & 0.961 \\
& $k_{1}=38.46 \mathrm{~min}^{-1}$ & \\
Pseudo-second-order & $q_{2}=2.3 \mathrm{mmol} \mathrm{g}^{-1}$ & 0.991 \\
& $k_{2}=0.03 \mathrm{~g} \mathrm{mmol}^{-1} \mathrm{~min}^{-1}$ &
\end{tabular}

equation is more similar to the experimental value than that of $q_{1}$. It indicated that the kinetics of $\mathrm{Au}(\mathrm{III})$ adsorption onto TSCSNC obeyed the pseudo-second-order model. The Lagergren pseudo-second-order kinetic model assumes that the ratelimiting step is the chemical adsorption. ${ }^{24}$
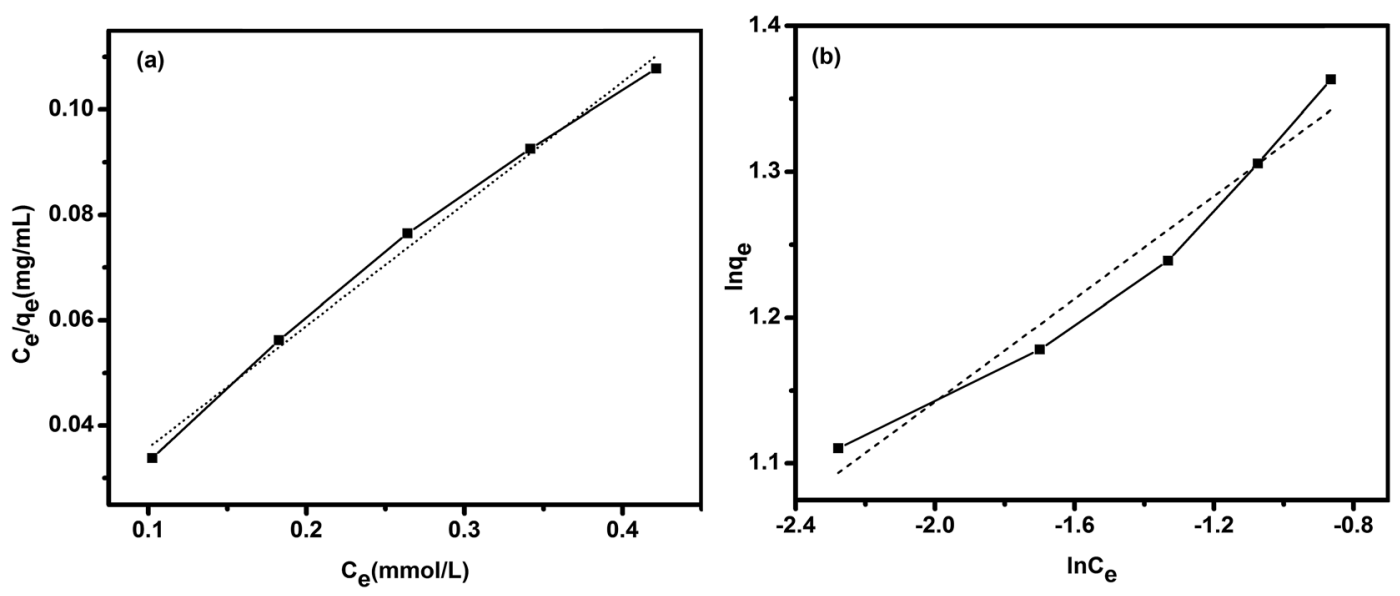

Fig. 8 Adsorption isotherms, (a) Langmuir model. (b) Freundlich model. 

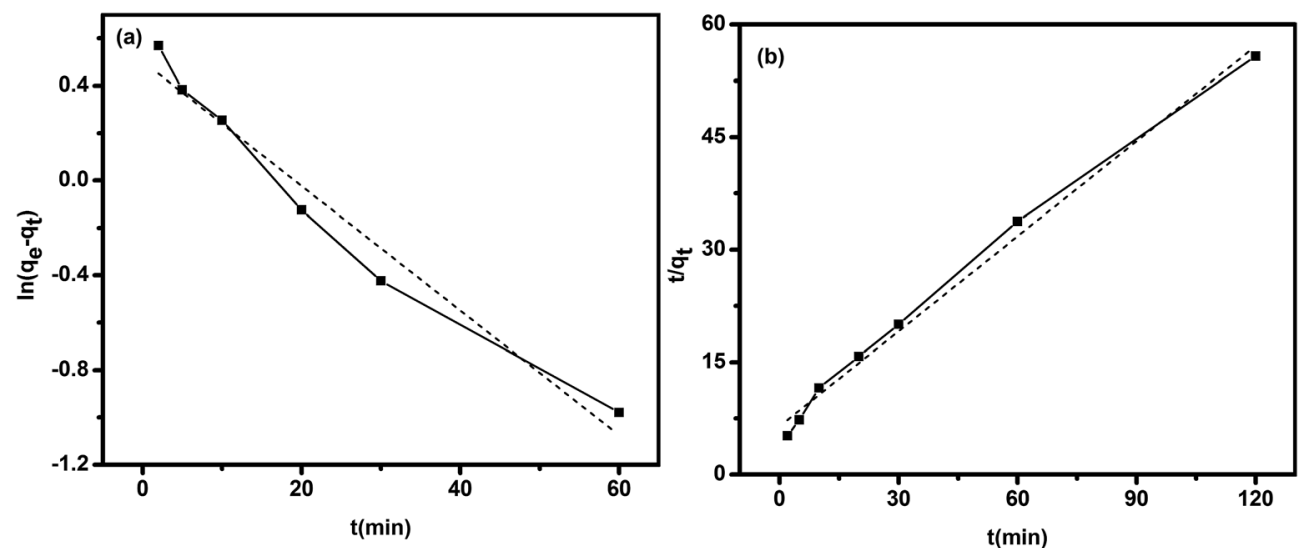

Fig. 9 Adsorption kinetic model (a) the pseudo-first-order adsorption kinetic model. (b) The pseudo-second-order adsorption kinetic model.

3.2.5 Adsorption mechanism of Au(III) onto TSC-SNC. To clarify the adsorption mechanism of Au(III) onto TSC-SNC, XPS studies of the adsorbent before and after the adsorption of $\mathrm{Au}$ (III) were carried out. In Fig. 2, the spectra of the $\mathrm{Au}$ (III) loaded TSC-SNC (defined as TSC-SNC-Au) appeared a new peak at about $88 \mathrm{eV}$ corresponding to $\mathrm{Au} 4 \mathrm{f}$, which indicated that $\mathrm{Au}$ (III) was adsorbed onto the surface of the adsorbent. And the peak at $202 \mathrm{eV}$ corresponding to $\mathrm{Cl} 2 \mathrm{p}$ suggested that gold was adsorbed as chloride complex. The appearance of $\mathrm{Au} 4 \mathrm{~d}$ peak at $353 \mathrm{eV}$ indicated that a portion of $\mathrm{Au}(\mathrm{III})$ ions were adsorbed due to ionic interaction. ${ }^{1}$
The high resolution spectra of $\mathrm{N} 1 \mathrm{~s}$ and $\mathrm{S} 2 \mathrm{p}$ of TSC-SNC and TSC-SNC-Au are shown in Fig. 10. The N 1s spectrum of TSCSNC can be curve-fitted into peaks at 398.6, 399.4 and $400.1 \mathrm{eV}$, corresponding to $\mathrm{C}=\mathrm{N},-\mathrm{NH} /-\mathrm{NH}_{2}$ and $-\mathrm{NH}_{2}{ }^{+}$species, respectively. Fig. 10b shows that the binding energy of $-\mathrm{NH} /-\mathrm{NH}_{2}$ groups $(400.2 \mathrm{eV}$ ) increased after $\mathrm{Au}(\mathrm{III})$ was adsorbed on the nanocomposite. This indicated that the amino groups were key factor for coordinating with $\mathrm{Au}(\mathrm{III})$. A broader peak of $-\mathrm{NH}_{2}{ }^{+}$ suggested that the most amino groups were protonated in acidic condition. The gold complex anions, therefore, can be adsorbed to the nanocomposite by ionic interaction.

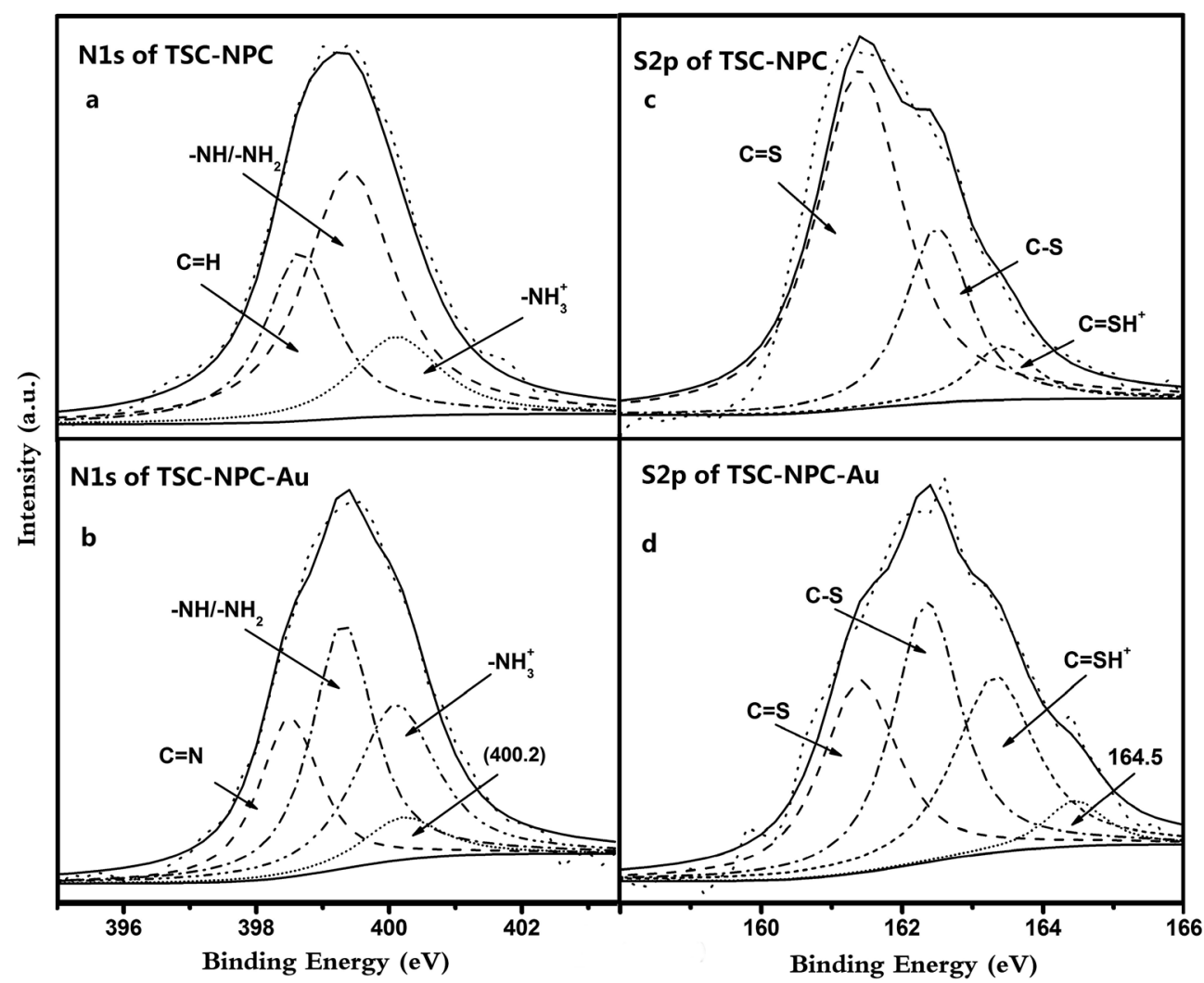

Fig. 10 The high-resolution core-level spectra of N 1s and S 2ps for TSC-SNC and TSC-SNC-Au. 


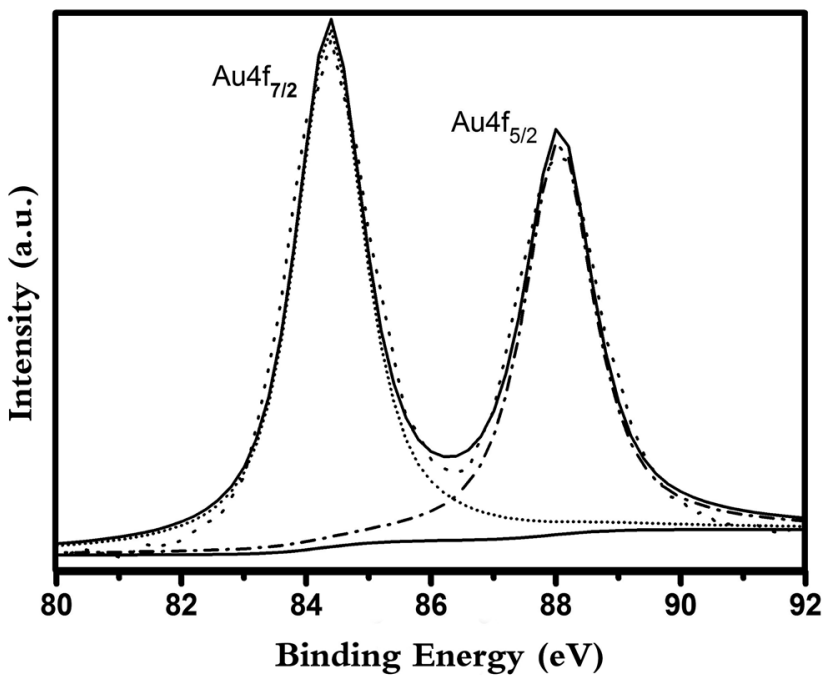

Fig. 11 The high-resolution core-level spectra of Au 4 in TSC-SNCAu.

In Fig. 10c, the XPS spectra of S $2 p$ were curve-fitted into three different component peaks at 161.4, 162.5 and 163.4 assigning to $\mathrm{C}=\mathrm{S}, \mathrm{C}-\mathrm{S}$ and $\mathrm{C}=\mathrm{SH}^{+}$species, respectively. After $\mathrm{Au}(\mathrm{III})$ adsorption, the $\mathrm{C}-\mathrm{S}$ binding energy of a portion of $\mathrm{C}-\mathrm{S}$ shifted from 162.5 to $164.5 \mathrm{eV}$, indicating that the thiol groups coordinated with $\mathrm{Au}(\mathrm{III})$. In addition, the protonation effect broadened the peak of $\mathrm{C}=\mathrm{SH}^{+}$, which indicated that the protonated thioamide groups were attracted gold complex anions.

The signal of $\mathrm{Au} 4 \mathrm{f}$ is presented in Fig. 11. The binding energy of $\mathrm{Au} 4 \mathrm{f}$ around 88.9 and $85.4 \mathrm{eV}$ in TSC-SNC-Au were much lower than that in $\mathrm{Au}(\mathrm{III})$. This result indicated $\mathrm{Au}$ (III) accepted electrons in the chelating process. So we proposed two mechanisms of $\mathrm{Au}(\mathrm{III})$ ions adsorption, one is $\mathrm{Au}(\mathrm{III})$ complexing with the thiol and amino groups, the other is the ionic

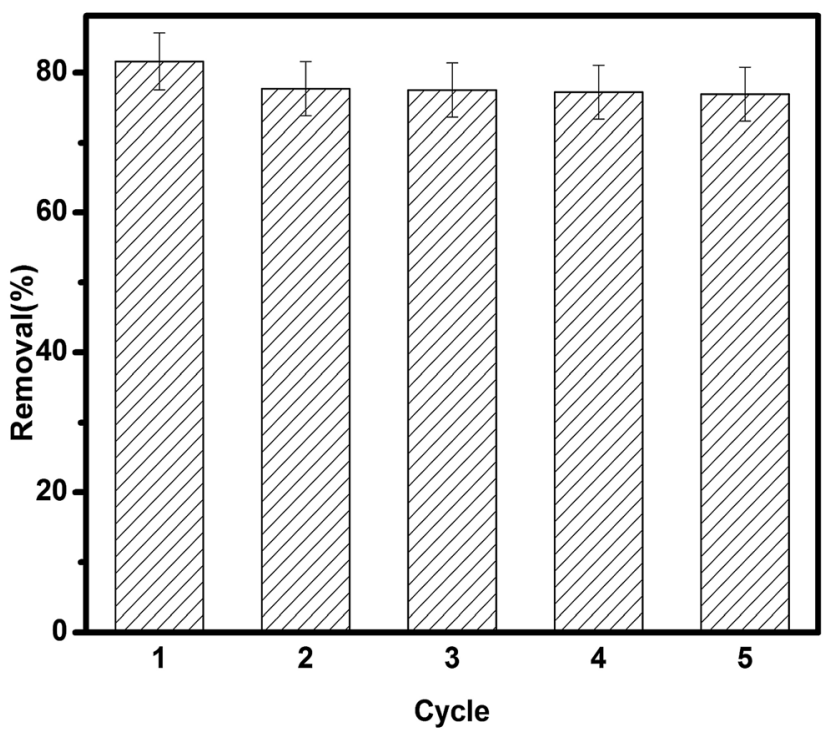

Fig. 12 Regeneration study of 5 cycles. interaction between the protonated groups and the gold complex anions. The $\mathrm{Au}(\mathrm{III})$ adsorption is due to the synergistic effect of ionic interaction and chelation.

3.2.6 Desorption and recycling. The recycling of the adsorbent is very important to its practical application. Fig. 12 shows the Au(III) adsorption on the TSC-SNC in five successive cycles of desorption/adsorption process. It can be seen that there is slightly decrease of the removal percent of $\mathrm{Au}$ (III) after five cycles, indicating the TSC-SNC adsorbent have good recycling.

\section{Conclusions}

In conclusion, we have developed a procedure for selective removal of $\mathrm{Au}(\mathrm{III})$ from aqueous solution using thiosemicarbazide/nanosilica composite synthesized via crosslinking the thiosemicarbazide with glutaraldehyde onto the surface of the amino functionalized silica nanoparticles. The highest $\mathrm{Au}$ (III) uptake value was obtained for $4.3 \mathrm{mmol} \mathrm{g}^{-1}$ at $\mathrm{pH}$ 2. The TSC-SNC nanocomposite showed higher affinity toward $\mathrm{Au}$ (III) compared with other $\mathrm{Pb}$ (II), $\mathrm{Cu}$ (II) and $\mathrm{Zn}$ (II) ions. The $\mathrm{Au}(\mathrm{III})$ adsorption on TSC-SNC obeyed the pseudo-second-order kinetics model and the equilibrium data was well fitted by the Langmuir models. The high selective $\mathrm{Au}(\mathrm{III})$ adsorption indicates that a synergistic effect of ionic interaction and chelation exists between $\mathrm{Au}(\mathrm{III})$ and TSC-SNC nanocomposites. The adsorbent showed high durability and easy regeneration. Efforts in our group are being made to extend current work to applications in recovery of noble metal ions. We anticipate this TSC-SNC nanocomposites to find uses in the field of environmental protection and secondary resource recovery.

\section{Conflicts of interest}

There are no conflicts to declare.

\section{Acknowledgements}

The authors are grateful for the financial support from the National Natural Science Foundation (No. 51664037) and Research Fund for Advanced Talents (No. 163083).

\section{References}

1 L. J. Pang, R. Li, Q. H. Gao, J. T. Hu, Z. Xing, M. X. Zhang, M. H. Wang and G. Z. Wu, Functionalized and reusable polyethylene fibres for $\mathrm{Au}(\mathrm{III})$ extraction from aqueous solution with high adsorption capacity and selectivity, $R S C$ Adv., 2016, 6, 87221-87229.

2 J. Jiang, Y. He, H. Gao and J. Wu, Solvent extraction of gold from alkaline cyanide solution with a tri-octylamine/tributyl phosphate/-heptane synergistic system, Solvent Extr. Ion Exch., 2005, 23, 113-129.

3 L. Guo, C. Liu, Z. Guo, L. Sun and J. Liu, Preparation of polyvinyl chloride-based thiosemicarbazide resin and its selective adsorption of $\mathrm{Ag}(\mathrm{I})$ and $\mathrm{Au}(\mathrm{III}), \mathrm{J}$. Dispersion Sci. Technol., 2012, 33, 690-696. 
4 K. Kashefi, J. M. Tor, K. P. Nevin and D. R. Lovley, Reductive precipitation of gold by dissimilatory Fe(III)-reducing bacteria and archaea, Appl. Environ. Microbiol., 2001, 67, 3275-3279.

5 A. Kargari, T. Kaghazchi, B. Mardangahi and M. Soleimani, Experimental and modeling of selective separation of gold(III) ions from aqueous solutions by emulsion liquid membrane system, J. Membr. Sci., 2006, 279, 389-393.

6 Q. Xu, P. Yin, G. Zhao, Y. Sun and R. Qu, Adsorption selectivity and dynamic adsorption behaviors of $\mathrm{Cu}(\mathrm{II})$, $\mathrm{Ag}(\mathrm{I})$, and $\mathrm{Au}(\mathrm{III})$ on silica gel encapsulated by amino functionalized polystyrene, J. Appl. Polym. Sci., 2010, 117, 3645-3650.

7 A. M. Donia, A. A. Atia and K. Z. Elwakeel, Gold(III) recovery using synthetic chelating resins with amine, thio and amine/mercaptan functionalities, Sep. Purif. Technol., 2005, 42, 111-116.

8 L. Zhang, Z. Li, X. Du and X. Chang, Activated carbon functionalized with 1-amino-2-naphthol-4-sulfonate as a selective solid-phase sorbent for the extraction of gold(III), Microchim. Acta, 2011, 174, 391.

9 E. Ertan and M. Gülfen, Separation of gold(III) ions from copper(II) and zinc(II) ions using thiourea-formaldehyde or urea-formaldehyde chelating resins, J. Appl. Polym. Sci., 2009, 111, 2798-2805.

10 C. Mack, B. Wilhelmi, J. R. Duncan and J. E. Burgess, Biosorption of precious metals, Biotechnol. Adv., 2007, 25, 264-271.

11 P. K. Jal, S. Patel and B. K. Mishra, Chemical modification of silica surface by immobilization of functional groups for extractive concentration of metal ions, Talanta, 2004, 62, 1005-1028.

12 P. A. Kumar, M. Ray and S. Chakraborty, Hexavalent chromium removal from wastewater using aniline formaldehyde condensate coated silica gel, J. Hazard. Mater., 2007, 143, 24-32.

13 L. S. Khabbaz, M. Hassanzadeh-Khayyat, P. Zaree, M. Ramezani, K. Abnous and S. M. Taghdisi, Detection of kanamycin by using an aptamer-based biosensor using silica nanoparticles, Anal. Methods, 2015, 7, 8611-8616.

14 S. H. Araghi and M. H. Entezari, Amino-functionalized silica magnetite nanoparticles for the simultaneous removal of pollutants from aqueous solution, Appl. Surf. Sci., 2015, 333, 68-77.

15 T. A. Yousef, G. El-Reash, O. El-Gammal and R. A. Bedier, Synthesis, characterization, optical band gap, in vitro antimicrobial activity and DNA cleavage studies of some metal complexes of pyridyl thiosemicarbazone, J. Mol. Struct., 2013, 1035, 307-317.

16 A. Aydin, M. Imamoglu and M. Gulfen, Separation and recovery of gold(III) from base metal ions using melamineformaldehyde-thiourea chelating resin, J. Appl. Polym. Sci., 2008, 107, 1201-1206.

17 L. Zhang, Y. Liu, S. Wang, B. Liu and J. Peng, Selective removal of cationic dyes from aqueous solutions by an activated carbon-based multicarboxyl adsorbent, RSC Adv., 2015, 5, 99618-99626.
18 R. Ii, S. C. Baxter, M. Bode, J. K. Berch, R. N. Shah and K. D. Shimizu, Application of the Freundlich adsorption isotherm in the characterization of molecularly imprinted polymers, Anal. Chim. Acta, 2001, 435, 35-42.

19 A. M. Donia, A. A. Atia and K. Z. Elwakeel, Gold(III) recovery using synthetic chelating resins with amine, thio and amine/ mercaptan functionalities, Sep. Purif. Technol., 2005, 42, 111-116.

20 A. Ramesh, H. Hasegawa, W. Sugimoto, T. Maki and K. Ueda, Adsorption of gold(III), platinum(IV) and palladium(II) onto glycine modified crosslinked chitosan resin, Bioresour. Technol., 2008, 99, 3801-3809.

21 K. Fujiwara, A. Ramesh, T. Maki, H. Hasegawa and K. Ueda, Adsorption of platinum(Iv), palladium(II) and gold(III) from aqueous solutions onto L-lysine modified crosslinked chitosan resin, J. Hazard. Mater., 2007, 146, 39-50.

22 X. Chen, K. F. Lam, S. F. Mak and K. L. Yeung, Precious metal recovery by selective adsorption using biosorbents, J. Hazard. Mater., 2011, 186, 902-910.

23 J. Fu, Z. Chen, M. Wang, S. Liu, J. Zhang, J. Zhang, R. Han and $\mathrm{Q}$. $\mathrm{Xu}$, Adsorption of methylene blue by a highefficiency adsorbent (polydopamine microspheres): kinetics, isotherm, thermodynamics and mechanism analysis, Chem. Eng. J., 2015, 259, 53-61.

24 L. Bai, H. Hu, W. Fu, J. Wan, X. Cheng, Z. Lei, L. Xiong and Q. Chen, Synthesis of a novel silica-supported dithiocarbamate adsorbent and its properties for the removal of heavy metal ions, J. Hazard. Mater., 2011, 195, 261-275.

25 M. R. Nabid, R. Sedghi, R. Hajimirza, H. A. Oskooie and M. M. Heravi, A nanocomposite made from conducting organic polymers and multi-walled carbon nanotubes for the adsorption and separation of gold(III) ions, Microchim. Acta, 2011, 175, 315-322.

26 D. Parajuli, C. R. Adhikari, M. Kuriyama, H. Kawakita, K. Ohto, K. Inoue and M. Funaoka, Selective recovery of gold by novel lignin-based adsorption gels, Ind. Eng. Chem. Res., 2006, 45, 8-14.

27 P. Yin, C. Wang, Y. Yang, Y. Tian and Z. Yu, Thermodynamics and kinetics of $\mathrm{Au}(\mathrm{III})$ adsorption on silica gel chemically modified by diethylenetriamine bis(methylene phosphonic acid), J. Chem. Eng. Data, 2011, 56, 450-457.

28 A. M. Donia, A. A. Atia and K. Z. Elwakeel, Recovery of gold(III) and silver(I) on a chemically modified chitosan with magnetic properties, Hydrometallurgy, 2007, 87, 197206.

29 W. S. Wan Ngah and K. H. Liang, Adsorption of gold(III) ions onto chitosan and N-carboxymethyl chitosan: equilibrium studies, Ind. Eng. Chem. Res., 1999, 38, 1411-1414.

30 F. Li, C. Bao, J. Zhang, Q. Sun, W. Kong, X. Han and Y. Wang, Synthesis of chemically modified chitosan with 2,5dimercapto-1,3,4-thiodiazole and its adsorption abilities for $\mathrm{Au}(\mathrm{III}), \operatorname{Pd}(\mathrm{II})$, and $\mathrm{Pt}(\mathrm{IV})$, synthesis of chemically modified chitosan with 2,5-dimercapto-1,3,4-thiodiazole and its adsorption abilities for $\mathrm{Au}(\mathrm{III}), \mathrm{Pd}(\mathrm{II})$, and $\mathrm{Pt}(\mathrm{IV})$, J. Appl. Polym. Sci., 2009, 113, 1604-1610. 
$31 \mathrm{H}$. Tokuyama and A. Kanehara, Temperature swing adsorption of gold(III) ions on poly(N-isopropylacrylamide) gel, React. Funct. Polym., 2007, 67, 136-143.

32 N. V. Nguyen, J. Jeong, M. K. Jha, J. Lee and K. Osseo-Asare, Comparative studies on the adsorption of $\mathrm{Au}$ (III) from waste rinse water of semiconductor industry using various resins, Hydrometallurgy, 2010, 105, 161-167.

33 J. Sanchez, M. Hidalgo and V. Salvado, The selective adsorption of gold(III) and palladium(II) on new phosphine sulphide-type chelating polymers bearing different spacer arms: equilibrium and kinetic characterization, React. Funct. Polym., 2001, 46, 283-291.

34 L. Liu, S. Liu, Q. Zhang, C. Li, C. Bao, X. Liu and P. Xiao, Adsorption of $\mathrm{Au}(\mathrm{III}), \mathrm{Pd}(\mathrm{II})$, and $\mathrm{Pt}(\mathrm{IV})$ from aqueous solution onto graphene oxide, J. Chem. Eng. Data, 2013, 58, 209-216.

35 R. Qu, C. Sun, M. Wang, C. Ji, Q. Xu, Y. Zhang, C. Wang, $\mathrm{H}$. Chen and P. Yin, Adsorption of $\mathrm{Au}(\mathrm{III})$ from aqueous solution using cotton fiber/chitosan composite adsorbents, Hydrometallurgy, 2009, 100, 65-71.
36 X. Liao, M. Zhang and B. Shi, Collagen-fiber-immobilized tannins and their adsorption of Au(III), Ind. Eng. Chem. Res., 2004, 43, 2222-2227.

37 L. Liu, C. Bao, Q. Jia, P. Xiao, X. Liu and Q. Zhang, Preparation and characterization of chitosan/graphene oxide composites for the adsorption of $\mathrm{Au}(\mathrm{III})$ and $\mathrm{Pd}(\mathrm{II})$, Talanta, 2012, 93, 350-357.

38 K. F. Lam, C. M. Fong, K. L. Yeung and G. Mckay, Selective adsorption of gold from complex mixtures using mesoporous adsorbents, Chem.-Eng. J., 2008, 145, 185-195.

39 Y. Yu, J. Addai-Mensah and D. Losic, Chemical functionalization of diatom silica microparticles for adsorption of gold(III) ions, J. Nanosci. Nanotechnol., 2011, 11, 10349-10356.

40 P. Yin, Q. Xu, R. Qu and G. Zhao, Removal of transition metal ions from aqueous solutions by adsorption onto a novel silica gel matrix composite adsorbent, J. Hazard. Mater., 2009, 169, 228-232. 